\title{
A system to manage the allocation of MSc Dissertations at University of Minho
}

\author{
J.M. Cabral \\ Industrial Electronics Dept. \\ University of Minho \\ Guimarães, Portugal \\ cabral@dei.uminho.pt
}

\author{
J.G. Rocha \\ Industrial Electronics Dept. \\ University of Minho \\ Guimarães, Portugal \\ gerardo@dei.uminho.pt
}

\author{
H. Costa \\ Netmove - Comunicação Global \\ Porto, Portugal \\ helder@netmove.pt
}

\begin{abstract}
This paper describes the basis for the specification of an IT infrastructure, supported by a website, designed to manage the entire paperwork process associated with the management of Masters Dissertations. With this infrastructure it is possible to disclose the subjects offered, to allocate each subject to a candidate - "dissertations in progress", browse dissertations that are awaiting review and consult the archive of dissertations with exams already carried out. PostgreSQL technology was used to support the databases. This technology was chosen to be robust, with easy integration with PHP and its code is open source. The website is housed in a Linux server based infrastructure ready to run continuously.
\end{abstract}

Keywords - CMS - Content Management System, Website, Backoffice, Frontoffice, PHP, Bologna Process, Dissertation

\section{INTRODUCTION}

The higher education systems have undergone great challenges in the last decades, initially motivated by the growing up number of students. Currently, the importance of communication technologies is found in the strong dissemination of knowledge, which has been taking place in the European systems, through the Bologna Process. The Bologna Process is named after the Bologna Declaration, which was signed in the Italian city of Bologna on June $19^{\text {th }}$ of 1999 by ministers in charge of higher education from 29 European countries [1].

The Bologna Declaration leads to the adoption of a system essentially based on two main cycles, undergraduate and graduate. The access to the second cycle hall requires successful completion of first cycle studies, lasting a minimum of three years. The second cycle should lead to the writing of a master thesis.

The dissertation topics are proposed by the advisors. The students then choose one topic from the whole list of topics available. When a dissertation topic is assigned to a given student, by his supervisor, the work process starts and lasts until the dissertation report is finished. After the supervisor approval, the dissertation is submitted to an examination which will be evaluated by a jury that will award a final mark. Finally, after the exam, the dissertation document is put in an electronic archive.
In order to manage this process an information system based on a website has been created, using the PHP programming language [2]. The website is divided into two main components: the Frontoffice and the BackOffice.

\section{A. Frontoffice}

This structure enables the students and the public to browse dissertation subjects offered by supervisors, the dissertations that are in progress, the ones that are waiting review and the archive of the dissertations already carried out. A news area is also available where the site administrator can broadcast some pertinent alerts and events related with the course. In order that a visitant can easily find a particular topic, a search engine was developed since the amount of information is growing everyday.

\section{B. Backtoffice}

This is a CMS (Content Management System) that is supported through a database (whose relation model is showed in figure 13).

The CMS enables the creation of a hierarchical structure of users, with different types of privileges, in order to manage the introduction of different kinds of data. Its main features are:

- The administrator is the one that has privileges to create the other users (supervisors) and each user is responsible to manage data related with the dissertations for which he is responsible. All users may introduce personal data associated with a particular student, but when a student is allocated to a specific user only this user and administrator can change this record.

- A file upload system was built since it is necessary to attach some other useful information supported in files (e.g. Photos, PDFs).

- In order to produce the student invoice form it was developed a tool that collects all the information related with the student (e.g. identification, address, birth, contacts, photo), the dissertation subject (e.g. description, objectives, tasks, schedule), the supervisor and other institutional data to produce a PDF file with a layout in accordance with the administrations office. 
The remaining blocks of the CMS support the introduction of contents that can be assessed through the Frontoffice.

\section{FRONTOFFICE DESCRIPTION}

The Frontoffice is a web based system that provides an interface to the students and supervisors in order to manage the dissertation process. The structure of the Frontoffice is composed by the following areas:

- Proposals: subjects offered by supervisors,

- Dissertations: dissertations in progress,

- Archive: dissertations already carried out,

- News: page to broadcast news,

- Documents: download area. Here are available all the files related to the registration process, assessments and some other logistics tasks,

- Search: typical search engine in order to easily find some particular topic (e.g. "find all topics proposed by a particular supervisor").

Fig. 1 shows the Frontoffice Homepage:

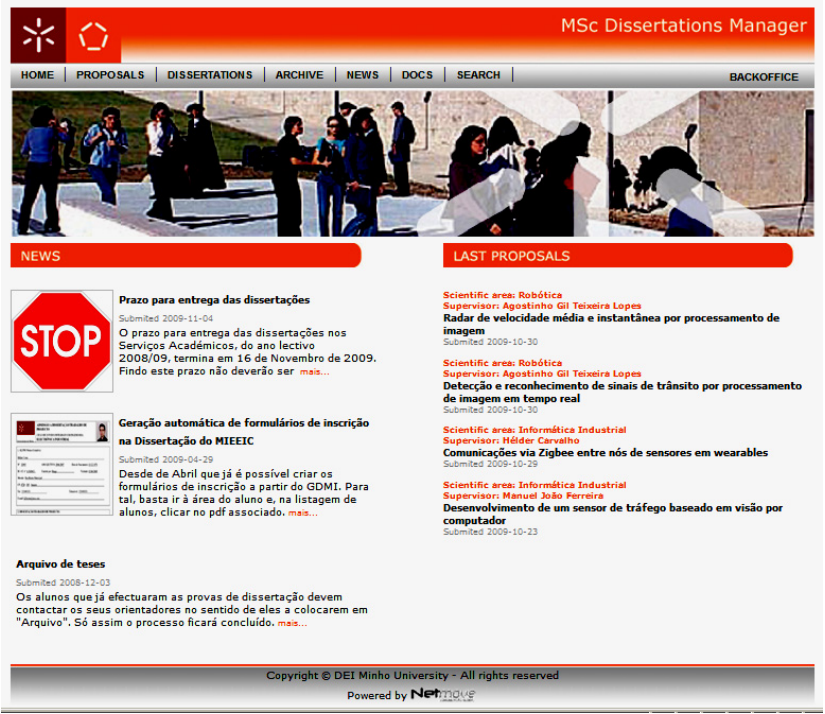

Figure 1. Frontoffice's Homepage.

The menu bar located at the top of the page is composed by the buttons to access all the areas mentioned above. There is also a button ("Backoffice") that opens a new window to Backoffice access.

The News area is located at the left side of the page. An event, an alert or a deadline can be announced here. The news structure has the following fields: Title, Date, Text and a Picture (optional). Only the first 25 words are displayed in the Homepage. To access to the whole news text it is necessary to press "more".

The right side of the screen is designed to show the last introduced proposals by the supervisors. When an exam is at a distance of 1 week, the right part of the screen is subdivided into two parts (fig. 2). Upper part has the reference(s) to the dissertation(s) (Title, Student Name, Exam date, Room and time). To access to all details of the dissertations (including the full text in PDF format) the user must follow the corresponding link.

The page showing dissertation details is presented in fig. 4 .

The remaining lower part of the page displays the last introduced proposals by the supervisors.

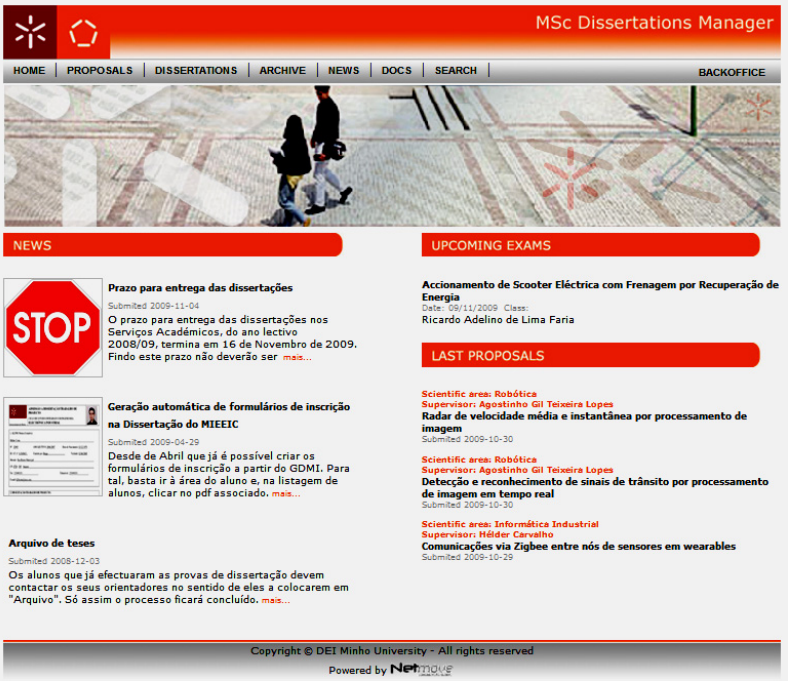

Figure 2. Frontoffice's Homepage. The right side of the page is now splitted into two parts to announce the upcoming exams.

The next area that can be accessed through the menu bar is the "Dissertations Proposals", by pressing "Proposals" button. The page is shown in fig. 3 .

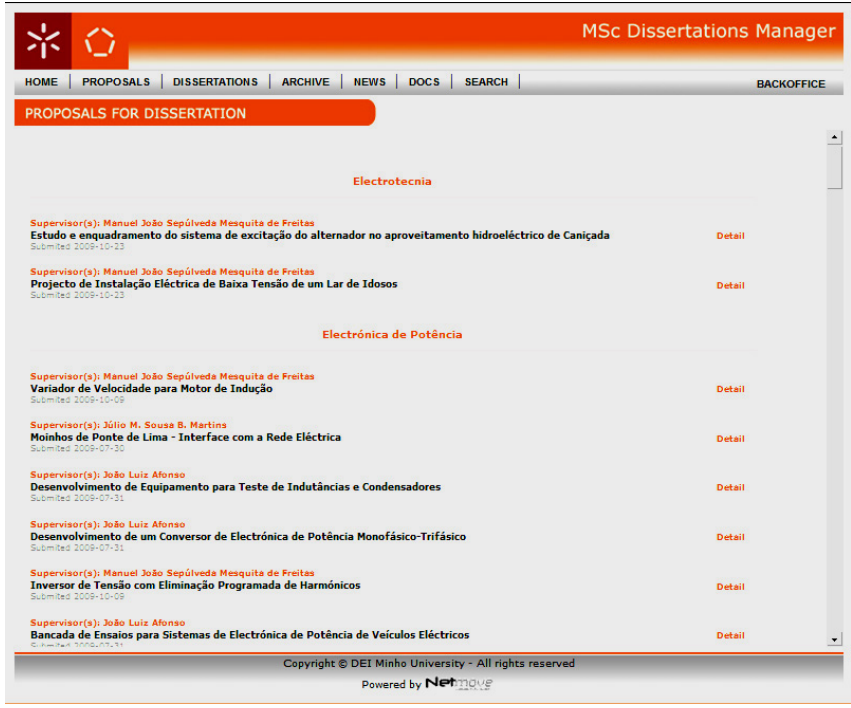

Figure 3. Dissertations Proposals list.

The result is a list of topics disposed by scientific areas. For each topic the Supervisor Name, the Title and the Submission Date are displayed. 
In order to view each proposal details, the user must press "Detail". The result is shown in fig. 4.

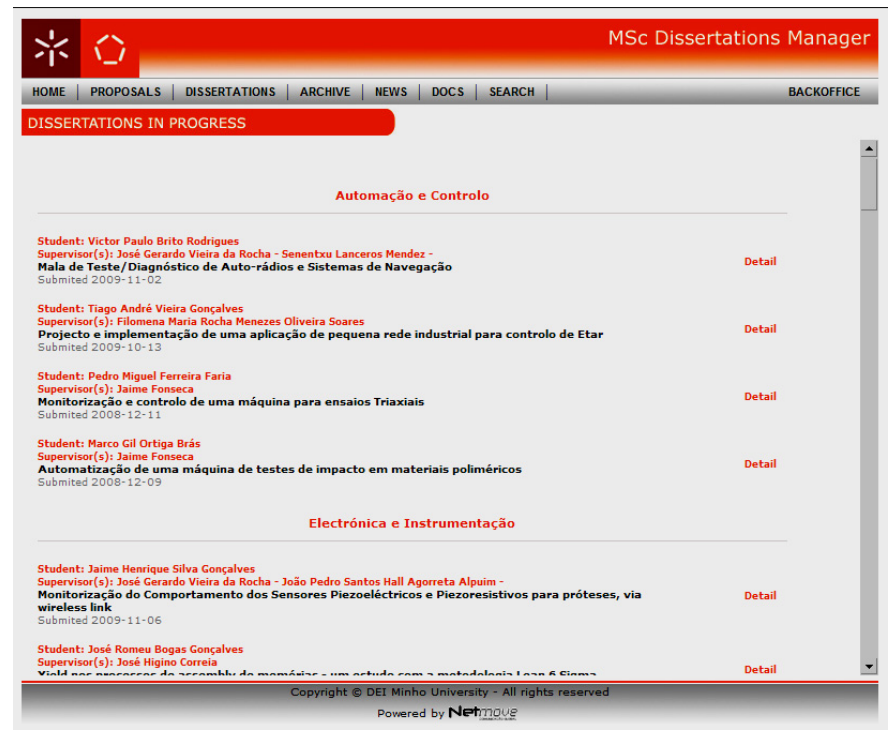

Figure 4. Dissertation Proposal details.

This page displays the full record of a chosen proposal. In fig. 4 we can see an example. The fields associated to each proposal are:

- Supervisor Name,

- $\quad$ Supervisor Email,

- Summary,

- Objectives,

- Keywords,

- Useful Links.

These fields must contain all the information that a student needs to select the theme that better fits to his skills and knowledge. After that, the student contacts the supervisor responsible for the chosen topic and discusses with him about the possibility (or not) of modifying the proposal in order to better fit the student profile. The result is then published in the Dissertations area.

The Dissertations area is similar to the Proposals area. The record structure contains all the fields (copied form the Proposals area) and other fields related to the allocated student:

- Student Number,

- Student Name,

- $\quad$ Student Email,

- $\quad$ Starting Date.

When the work is terminated the student writes his dissertation and a jury, recommended by the Department's Academic Board, is appointed. The Jury is usually composed by the student's supervisor, the head of department and an invited professor from another department or faculty, that will be the Reporter of the examination. At this time some more information are appended to the Dissertations area:

- Reporter Name,

- Reporter Email,

- Exam date,

- Exam location,

- Dissertation text in PDF format.

Fig. 5 shows an example of a Dissertation page in full format:

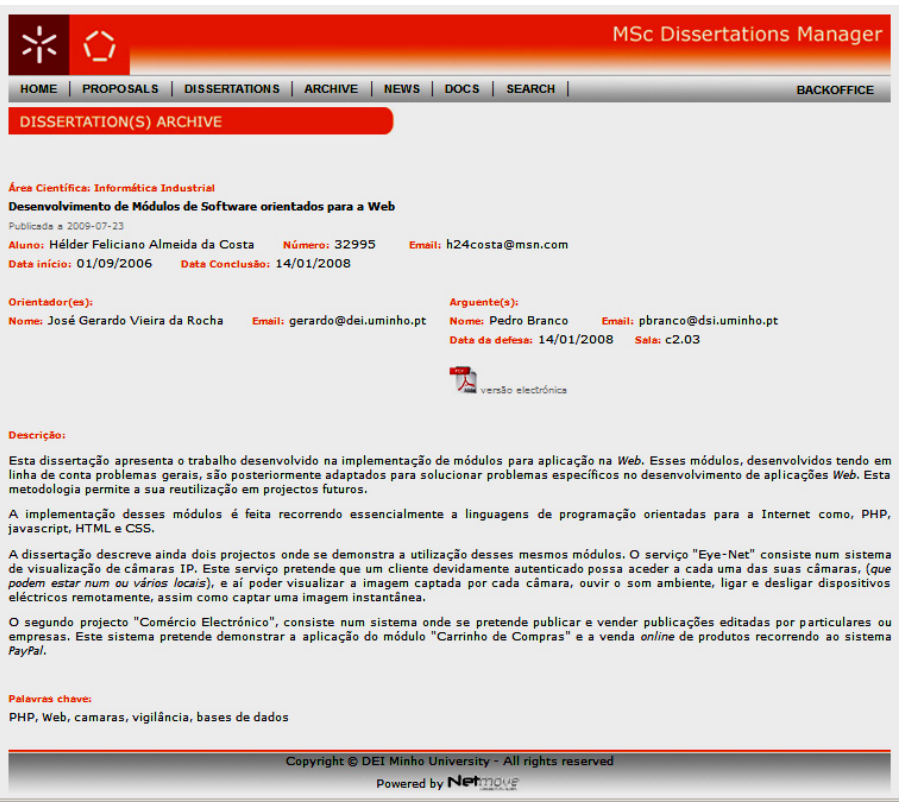

Figure 5. Dissertation page in full format.

This page is displayed in the Dissertations area until the exam date is reached. After that, this record is moved to archive. The layout and the information remain the same as previously, but the record belongs now to Archive area.

The News area consists of a page where the news, listed in reverse order of entry, are displayed in the same way as in fig.1, but now enjoying the whole space of the page.

The Documents area is a file repository that stores some useful forms, templates, tutorials and some dissertation rules and guidelines to help and support students during the whole process.

Finally, pressing "Search" at a menu bar, a page with a search engine is accessed (Fig. 6). This page is very useful since the amount of information is growing quickly.

Here it is possible to find dissertations or proposals. The search can be done by Student or Supervisor names, Scientific area or a given keyword. 


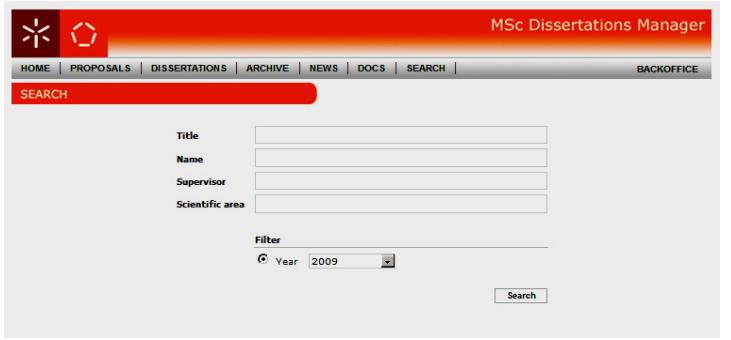

Figure 6. Search engine page.

\section{BACKOFFICE DESCRIPTION}

The Backoffice is CMS that manage all the information that can be accessed by the Frontoffice. The login page is accessed by pressing the "Backoffice" button located in the right corner of the menu bar. The Login page is shown in fig. 7.

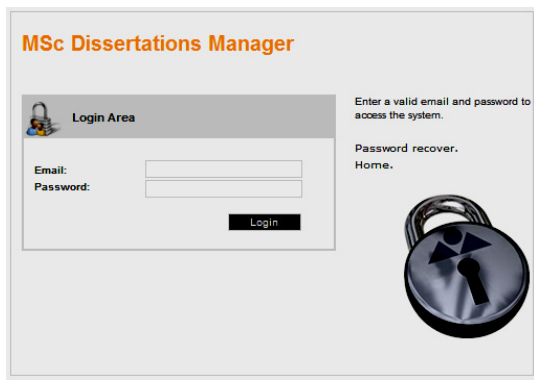

Figure 7. Backoffice Login page.

By entering the user's email and password, the system goes to the Backoffice Homepage. Fig. 7 shows that homepage when a user is logged in.

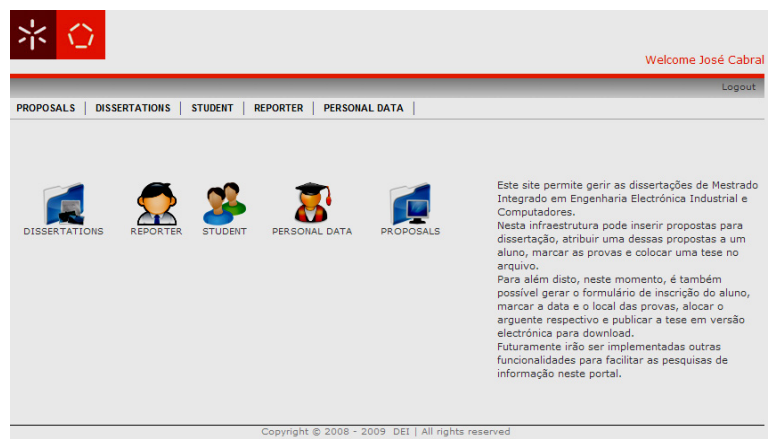

Figure 8. Backoffice Homepage (user).

The Menu bar is composed by five buttons:

- Proposals,

- Dissertations,

- Students,

- Reporters,

- Personal data.

The Proposals area is a page that contains a form with the fields required to be filled with the information related with the proposed work. Fig. 9 shows the Proposals page.

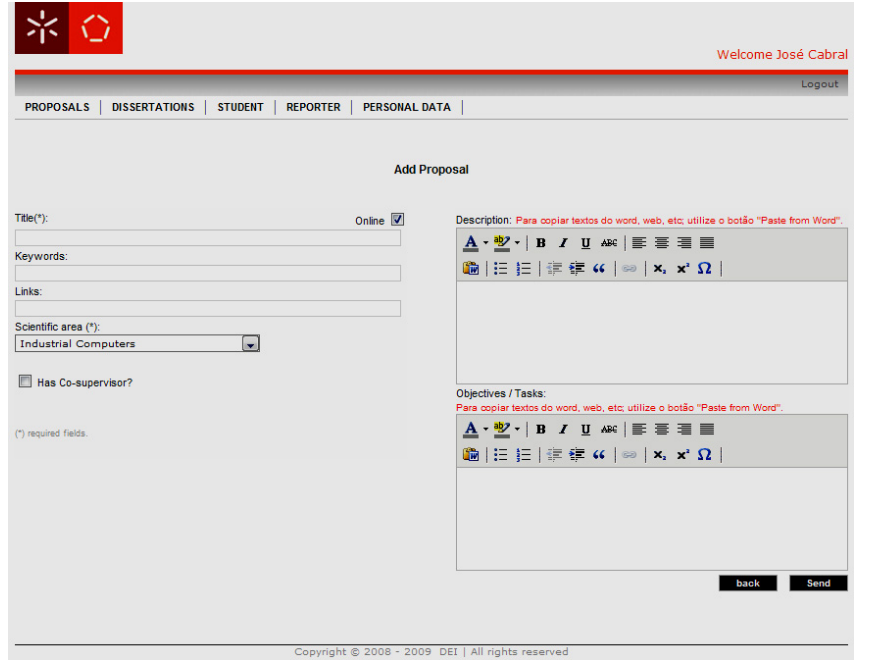

Figure 9. Proposals page.

The text inserted in fields "Description" and "Objectives" could be formatted using an editor tool visible at the right side of fig. 9. The other fields are inserted using basic text boxes. There is also a checkbox ("offline") to show/hide the proposal in Frontoffice.

The Dissertations page structure contains all the fields of the Proposals page and other information related with the student. When a student has finished his work, the supervisor activates a checkbox to define the exam schedule. This action expands the form in order to insert other fields associated with the exam:

- Exam Date,

- Room and Time,

- Reporter name,

- Upload PDF.

Fig. 10 shows the expanded Dissertations page layout.

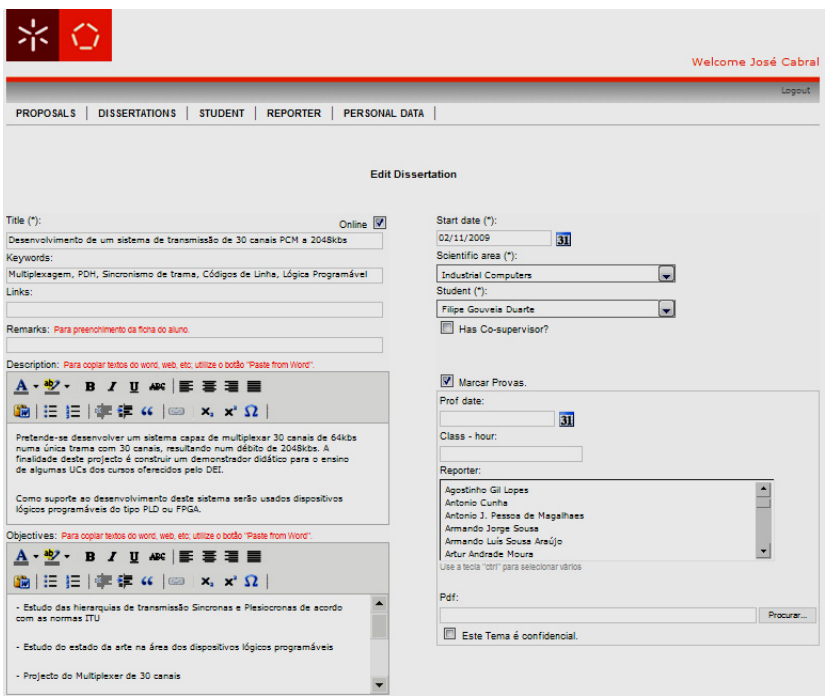

Figure 10. Dissertations page (expanded). 
The next item at the Menu bar is the "Student" button. Pressing this button the system displays the page shown in fig. 11.

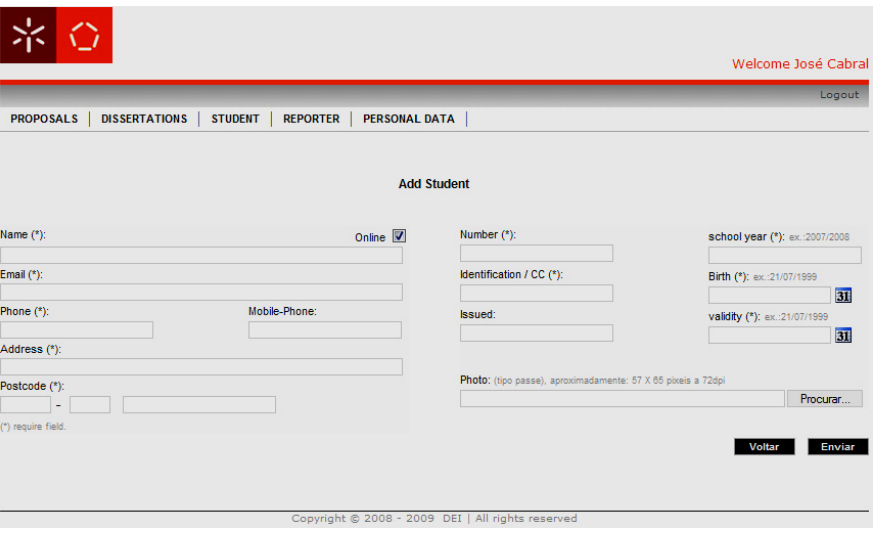

Figure 11. Student page

In this page there is a form to introduce the student data as well as an upload box to collect the student photo.

The remaining buttons of fig. 9 ("Reporter" and "Personal Data") are also forms to introduce personal information about the reporter of the exam and the user, respectively.

Since the Administrator needs additional tools in order to create, delete or change settings of regular users, create news and change a user profile, his menu bar has more buttons when compared with the one of a normal user. Moreover, a user with an administrator profile may access to the information introduced by all users. Fig. 12 shows the Backoffice's Homepage in this case.

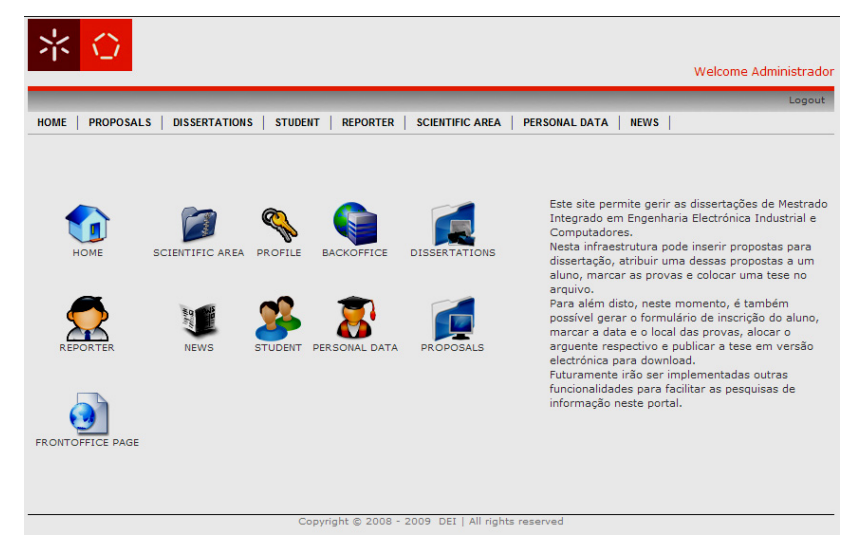

Figure 12. Backoffice Homepage (Administrator).

The extra buttons are:

- Personal Data,

- News.

The first button also appears when a normal user is logged in but, in this case, the Administrator has a tool that allows him to create new users with one of two profiles: "Normal user" and "Administrator". The second button produces a form that allows him to introduce the texts and the images associated to the news area of the Frontoffice.

\section{Supporting TECHNOLOGIES}

System development was supported mainly by two technologies: PHP and PostGreSQL, described in the next two sections.

\section{A. $P H P$}

PHP (Hypertext Preprocessor) is a widely-used generalpurpose open source scripting language that is especially suited for Web development and can be embedded into HTML (Hypertext Markup Language) [2]. PHP is mainly focused on server-side scripting and so it can do anything any other CGI (Common Gateway Interface) program can do, such as collect form data, generate dynamic page content, or send and receive cookies. There are three main areas where PHP scripts are used:

- Server-side scripting. This is the most traditional and main target field for PHP. There are three things to make this work: the PHP parser (CGI or server module), a web server and a web browser. When the web server is running, with a connected PHP installation, the PHP program output can be accessed with a web browser, viewing the PHP page through the server.

- Command line scripting. A PHP script can run without any server or browser. In this case it is only necessary the use of a PHP parser. This type of usage is ideal for scripts regularly executed using cron (on Unix or Linux) or Task Scheduler (on Windows). These scripts can also be used for simple text processing tasks.

- Writing desktop applications. PHP is probably not the very best language to create a desktop application with a graphical user interface, but for those who know PHP very well, and would like to use some advanced PHP features in client-side applications, they can also use PHP-GTK to write such programs.

One of the strongest and most significant features in PHP is its support for a wide range of databases. Writing a databaseenabled web page is incredibly simple.

\section{B. PostgreSQL}

PostgreSQL is a powerful, open source object-relational database system. It has more than 15 years of active development and a proven architecture that has earned it a strong reputation for reliability, data integrity, and correctness [3]. It runs on all major operating systems, including Linux, UNIX and Windows. It is fully ACID (Atomicity, Consistency, Isolation, Durability) compliant, has full support for foreign keys, joins, views, triggers, and stored procedures (in multiple languages). It includes most SQL:2008 data types, including INTEGER, NUMERIC, BOOLEAN, CHAR, VARCHAR, DATE, INTERVAL and TIMESTAMP. It also supports storage of binary large objects, including pictures, sounds, or video. It has native programming interfaces for $\mathrm{C} / \mathrm{C}++$, Java, .Net, Perl, Python, Ruby, Tcl, ODBC, among others, and exceptional documentation. 
An enterprise class database, PostgreSQL boasts sophisticated features such as Multi-Version Concurrency Control (MVCC), point in time recovery, tablespaces, asynchronous replication, nested transactions (savepoints), online/hot backups, a sophisticated query planner/optimizer, and write ahead logging for fault tolerance. It supports international character sets, multibyte character encodings, Unicode, and it is locale-aware for sorting, case-sensitivity, and formatting. It is highly scalable both in the sheer quantity of data it can manage and in the number of concurrent users it can accommodate. There are active PostgreSQL systems in production environments that manage in excess of 4 terabytes of data.

PostgreSQL's source code is available under the most liberal open source license: the BSD license.

\section{SUPPORTING DATABASE}

The supporting database was implemented in PostgreSQL whose relation model is shown in fig. 13.

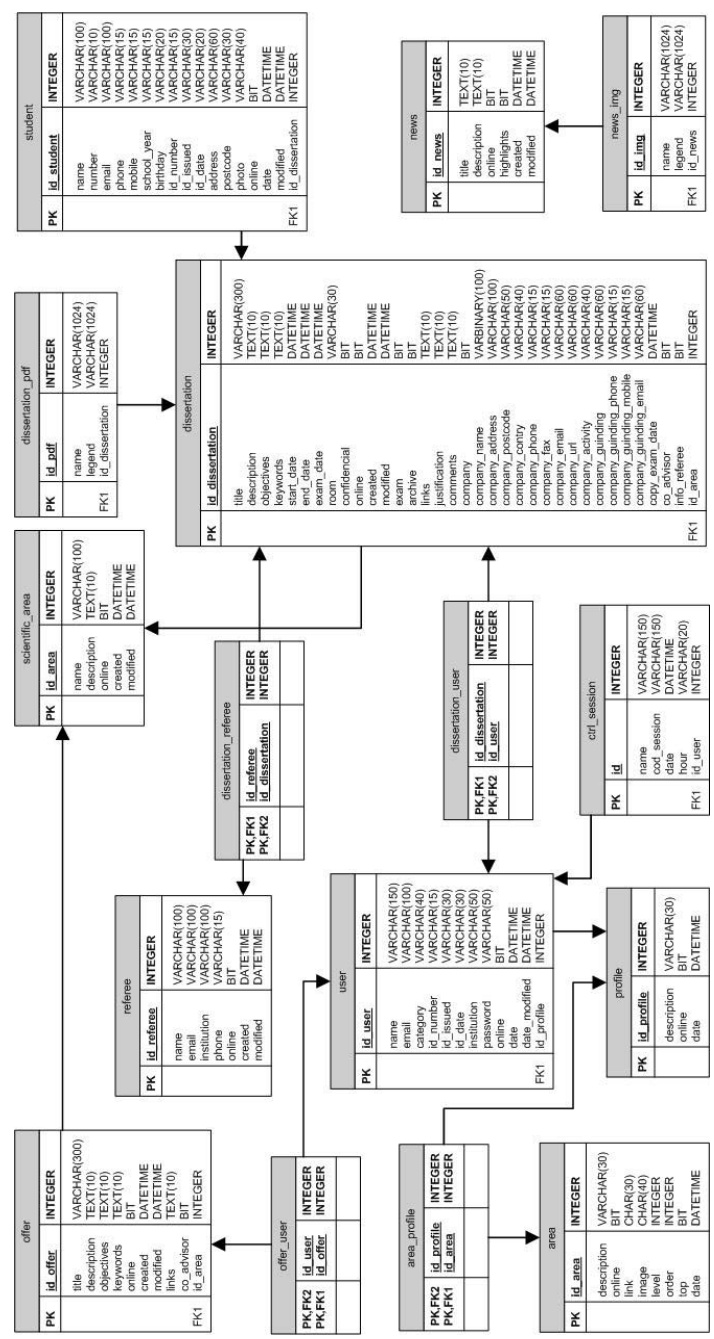

Figure 13. Database relational model.
This model is fully normalized and, thereby, ensures that the information will not be lost or duplicated. The model consists of 16 tables and could be divided in three groups.

The group, composed by tables: user, area_profile, profile, area, student and referee stores information about system users and are classified through a user profile with different privileges. Thus, it is possible to ensure that data entered by a particular user will not be corrupted by misuse.

The group, composed by tables: offer, dissertation, dissertation_pdf, scientific_area, news and news_img is responsible to store information that can be accessed in the Frontoffice such as: Proposals, Dissertations and News.

The other tables are used to troubleshoot impossible relationships in the system.

\section{CONCLUSIONS}

The specification of an IT infrastructure supported by a website, designed to manage the paperwork process associated with Masters Dissertations is described in this paper [6]. The infrastructure is composed by two main areas: the Frontoffice and the Backoffice. The first one allows all the people to browse the information about the past and present master thesis, whereas the second one allows the responsible people to introduce the information. PostgreSQL database manager with integration with PHP in a Linux server were used as supporting technologies. The system is full working at the University of Minho, having at this moment 230 registered Master students and dissertations.

\section{ACKNOWLEDGMENT}

The authors would like to thank Netmove - Comunicação Global, which gave the authors the technical support in PHP and PostgreSQL, developing this system in partnership with University of Minho.

\section{REFERENCES}

[1] Bologna Process (2009) Retrieved on March 10th, 2009 from http://www.ond.vlaanderen.be/hogeronderwijs/bologna/about/index.htm

[2] www.php.net

[3] http://www.postgresql.org/

[4] Matthew, N.; Stones, R.; "Beginning Databases with PostgreSQL: From Novice to Professional", Second Edition, Apress, 2005.

[5] Converse, T.; Park, J.; "PHP Bible", 2nd Edition. Wiley Publishing, Inc., 2002 .

[6] http://intranet.dei.uminho.pt/gdmi/en 